\title{
SCIENTIFIC GOALS OF OPTICAL INSTRUMENTS OF THE NATIONAL HELIOGEOPHYSICAL COMPLEX
}

\author{
R.V. Vasilyev \\ Irkutsk State University, \\ Irkutsk, Russia, roman_vasilyev@iszf.irk.ru \\ Institute of Solar-Terrestrial Physics SB RAS, \\ Irkutsk, Russia,roman_vasilyev@iszf.irk.ru
}

\section{M.F. Artamonov}

Institute of Solar-Terrestrial Physics SB RAS, Irkutsk, Russia,artamonov.maksim@iszf.irk.ru

\section{A.B. Beletsky}

Institute of Solar-Terrestrial Physics SB RAS,

Irkutsk, Russia, beletsky@isz.irk.ru

\section{O.S. Zorkaltseva}

Irkutsk State University,

Irkutsk,Russia,olgak@iszf.irk.ru

Institute of Solar-Terrestrial Physics SB RAS,

Irkutsk,Russia,olgak@iszf.irk.ru

\section{E.S. Komarova}

Irkutsk State University,

Irkutsk,Russia, eskomarik@gmail.com

Institute of Solar-Terrestrial Physics SB RAS,

Irkutsk, Russia, eskomarik@gmail.com

\section{I.V. Medvedeva}

Institute of Solar-Terrestrial Physics SB RAS,

Irkutsk,Russia,ivmed@iszf.irk.ru

\author{
A.V. Mikhalev \\ Irkutsk State University, \\ Irkutsk State University \\ Institute of Solar-Terrestrial Physics SB RAS, \\ Irkutsk, Russia,mikhalev@iszf.irk.ru \\ S.V. Podlesny \\ Institute of Solar-Terrestrial Physics SB RAS, \\ Irkutsk, Russia, step8907@mail.ru \\ K.G. Ratovsky \\ Institute of Solar-Terrestrial Physics SB RAS, \\ Irkutsk, Russia,ratovsky@iszf.irk.ru \\ T.E. Syrenova \\ Institute of Solar-Terrestrial Physics SB RAS, \\ Irkutsk,Russia,angata@iszf.irk.ru \\ M.A. Tashchilin \\ Institute of Solar-Terrestrial Physics SB RAS, \\ Irkutsk,Russia,miketash@iszf.irk.ru

\section{I.D. Tkachev} \\ Institute of Solar-Terrestrial Physics SB RAS, \\ Irkutsk, Russia, tid007@iszf.irk.ru
}

\begin{abstract}
Studies of the upper atmosphere have to be performed using optical photometric and spectrometric means. Modern devices allow precise photometry of the glow of the night atmosphere - airglow — with high temporal spatial and spectral resolution. As a result, the obtained airglow parameters make it possible to determine the physicochemical properties of the upper atmosphere and observe their variation under the influence of various factors. The National Heliogeophysical Complex, which is being created in Eastern Siberia, is therefore to include a certain set of modern optical instruments. The paper presents the main phenomena that will be investigated by the optical instruments of the complex, provides information on their composition and scientific goals, presents the results of preliminary studies performed using a prototype of the instruments. As a result of the studies, the presence of a significant (about $10 \mathrm{~m} / \mathrm{sec}$ ) vertical wind at various altitudes (100 and $250 \mathrm{~km}$ ) was established, the importance of taking into account the vertical wind to study the vertical dynamics of the charged component was demonstrated. The longterm dynamics of the vertical wind at an altitude of about $100 \mathrm{~km}$ has a pronounced seasonal variations and the absence of diurnal variations, whereas the dynamics of the vertical wind at an altitude of $250 \mathrm{~km}$ has a pro-
\end{abstract}

nounced diurnal variations, which is most clearly defined in winter. This suggests the presumed presence of vertical circulation cells at various altitude levels. The possibilities of optical stereoscopy and differential image analysis methods are demonstrated, as applied to the study of fast luminous formations and conducting active ground and space experiments to modify Earth's ionosphere. We report the results of the determination of a three-dimensional picture of a long-lived meteor trail with the use of two wide-angle cameras. We propose an algorithm that allows us to get a stereo image of events occurring in the upper atmosphere, recorded simultaneously from different observation points. The joint work of the tools of this complex and the development of cooperation with third-party organizations are shown to be a good enough direction for further study of the vertical dynamics of Earth's upper atmosphere and space weather phenomena.

Keywords: airglow, photometer, diffraction spectrometer, Fabry-Perot interferometer, all-sky camera, stereoscopy, horizontal wind, vertical wind, meteors, atmospheric electricity, artificial modification of the ionosphere.

\section{INTRODUCTION}

Airglow is generated by various processes: chemical reactions, electrical phenomena, thermomechanical effect, and others manifesting themselves to a greater or lesser extent virtually throughout Earth's atmosphere.
Observations and study of airglow are important to accomplish objectives of the research into its structure and dynamics because airglow characteristics are subject to variations arising from the motion of air masses, variations in their temperature and composition. The National 
Heliogeophysical Complex (NHC) under construction in Eastern Siberia for research in solar-terrestrial physics and space weather should therefore include instruments for recording optical radiation of the atmosphere. It is obvious that airglow will be recorded most effectively at night in the absence of the main source of background - direct solar emission. The night airglow contains several components: glow from deep space objects - stars and galaxies; sunlight reflected and scattered by planets of the solar system and gas-dust component surrounding Earth; meteor trails; glow generated by atmospheric electricity; glow caused by chemical reactions occurring in the upper atmosphere. The three last phenomena are the most interesting for research in solar-terrestrial physics and space weather.

The airglow caused by chemical reactions involving ozone, hydrogen, atomic oxygen, molecular oxygen ions, and nitric oxide, as well as elements of meteoric origin occurs due to radiative relaxation of excited products of these reactions - neutral oxygen, sodium, potassium atoms and hydroxyl molecules [Shefov and et al., 2006]. The chemiluminescent airglow is virtually time-continuous and has a wide spectrum consisting of bands and lines of emission of various elements constituting the atmosphere. Features of the reactions, different lifetimes determining conditions of nonradiative quenching of excited neutral components lead to distribution of the spectral composition of airglow with height - stratification of certain emission lines in the mesosphere and lower thermosphere. Thus, observations of characteristics of spectral composition and its dynamics are essential for the study of vertical profiles of parameters of the nightside atmosphere.

The glow from lightnings occurs due to the powerful pulse of electric current in the troposphere, which appears between charged clouds or between a cloud and the ground. In the lower atmosphere, this current causes gas to heat and glowing hot plasma to occur, whereas in the upper atmosphere (above $80 \mathrm{~km}$ ) airglow is caused by a rapid change of the electric field in a cold plasma due to tropospheric electric discharge [Cooray, 2015]. The spectrum of electromagnetic radiation from tropospheric lightnings is fairly wide - from long radio waves to $\mathrm{X}$ rays. The spectral composition of optical glow from lightning discharges (elves, sprites, etc.) mainly contains emission lines of molecular nitrogen vibration transitions lying in the red and infrared portions of the visible spectrum [Lu et al., 2017]. Changes in the chemical composition and physical conditions of the mesosphere - the region of maximum development of high-altitude lightning discharges - should have a significant effect on their parameters, therefore the research into these sporadic events is promising for the study of the upper atmosphere, space weather events, and solar-terrestrial relations.

Note that the tropospheric thunderstorm activity itself is also quite interesting for studies dealing with the influence of solar activity on weather and climate [Siingh et al., 2011; Nicoll, 2014]. The influence solar coronal mass ejections and related plasma streams exert on Earth's atmosphere involves changing the chemical balance of minor atmospheric components, which can lead to a change in the atmospheric aerosol formation dynamics, cloud cover variations, radiation imbalance, etc. As a consequence, these processes can alter the conditions of formation of thunderstorm regions, showing up in the interaction between thunderstorm and geomagnetic activities [Owens et al., 2015; Wu et al., 2019].

Meteoric phenomena generally occur at altitudes from 80 to $120 \mathrm{~km}$. The character of the interaction between a meteoroid and the atmosphere depends on its initial mass, velocity, and composition. An incoming particle flux heats a meteor, thus producing a bright flash of short duration from a fraction to a few seconds. Meteoroid destruction in the rarefied atmosphere occurs by ablation, or evaporation of atoms from its surface under the action of incoming air particles. After passing, a meteor leaves an ionized luminous trail from several hundreds of meters to several tens of kilometers long, which then moves (drifts) under the action of air currents. Such trails depending on their composition (dust, gas, plasma) can be seen in the atmosphere from a few seconds to several hours [McKinley, 1964; Kelley et al., 2000, Clemesha et al., 2001]. The meteor glow spectrum consists mainly of emission lines of atomic spectra with much weaker molecular bands. The most intense lines in the spectra contain $\mathrm{Fe}, \mathrm{Na}, \mathrm{Mg}, \mathrm{Mg}^{+} \mathrm{Ca}, \mathrm{Ca}^{+}, \mathrm{Cr}, \mathrm{Si}^{+}, \mathrm{N}, \mathrm{O}$ atoms and ions [Astapovich, 1958]. The spectrum of glow of longlived meteor trails is composed primarily of 589.0, 589.6 $\mathrm{nm}$ sodium doublet [Kelley et al., 2000], but there is evidence that the spectral composition of these structures also contains the glow of the main components of the upper atmosphere [Clemesha et al., 2001]. Since the optical glow maximum as a result of meteor impacts is realized in the lower thermosphere and in the mesosphere, variations in the intensity and spectral composition of meteor glow as well as the dynamics of long-lived meteor structures may be used to gain more information on the state of the upper atmosphere.

ISTP SB RAS started examining airglow at high latitudes at Norilsk Integrated Magnetic-Ionospheric Station $\left(70^{\circ} \mathrm{N}, 88^{\circ} \mathrm{E}\right)$ about fifty years ago [Gorelyi et al., 1977] and at middle latitudes at the Geophysical Observatory $(\mathrm{GPhO})$ near the village of Tory $\left(52^{\circ} \mathrm{N}\right.$, $103^{\circ} \mathrm{E}$ ) over 30 years ago [Ermilov, Mikhalev, 1989; Ermilov, Mikhalev, 1991]. Using airglow data nearreal-time and obtained over the past few decades, we perform a comparative analysis of airglow intensity variations with the dynamics of various phenomena in the lower and middle atmosphere, gain information on the development of mid-latitude aurora, temperature and wind speed in the lower thermosphere and at the mesopause, on wave processes of different scales in the upper atmosphere. ISTP SB RAS geophysical observatories are equipped today with the following instruments: quite modern prism and diffraction spectrometers detecting intensities of the main lines of chemiluminescent airglow; wide-angle color cameras; super-wide-angle system recording atomic oxygen emission at a wavelength of $630 \mathrm{~nm}$ (all-sky camera); Fabry-Perot interferometer adapted for aerodynamic research; AERONET sun photometer. Note that the configuration of the currently available optical instruments does not 
allow for full simultaneous observations of parameters of different spectral lines and stereoscopy of glowing structures for a detailed study of the vertical dynamics of the atmosphere. Moreover, the sensitivity of recording elements in most instruments is sufficient only for relatively long exposures of a few minutes, whereas some current objectives of research into the upper atmosphere require second and subsecond temporal resolution.

The development of NHC - a new integrated scientific object in the Baikal region - involves a significant renewal of the currently available optical instruments of ISTP SB RAS. This will considerably expand existing monitoring capabilities. An opportunity will arise to make simultaneous observations of parameters of the main lines of airglow, spatial pattern of airglow in different spectral lines. Spacing of existing and new systems at some distance will allow for stereoscopic studies of glowing structures. Optical and radiophysical observations of the entire atmosphere will enable us to examine the interaction between neutral and charged components in the upper atmosphere under different geophysical conditions. Multispectral optical observations, lidar and radar observations will provide the vertical picture of the interaction between charged and neutral components practically from the stratosphere to the thermosphere. Ionosphere modification by powerful HF radiation of the new heating facility, developed under NHC, or by chemicophysical action of various satellite aids, as well as supplementing these studies with consistent optical and radiophysical observations of vertical profiles will enable us to study processes in the upper atmosphere at a new level.

The paper discusses the configuration of NHC optical instruments under commissioning and their role in future studies of the upper atmosphere, space weather, and solarterrestrial physics.

\section{RESEARCH OBJECTIVES OF THE OPTICAL INSTRUMENTS}

Research objectives of the NHC optical instruments deal with a large range of phenomena and processes occurring in Earth's upper atmosphere and ionosphere [Shefov et al., 2006]. Among the most relevant ones is the research into strong geomagnetic storms, sudden winter stratospheric warming (SSW) events, solar activity, climate changes, other geophysical events, and anthropogenic effect.

The NHC optical instruments make up a complex allowing for the accomplishment of the said research objectives in at least two directions. One of them is to examine characteristics of natural airglow and to compare the observed airglow parameters with physicochemical processes in the atmosphere under the action of external and internal factors (solar and geomagnetic activities, interaction between the ocean and the atmosphere, lithospheric processes). Another direction is to supplement integrated active research on modification of the upper atmosphere with radiophysical devices, satellite and rocket facilities.

To maximize the effectiveness of the NHC observation instruments, optical instruments of the complex are installed in $\mathrm{GPhO}$, where their fields of view will maximally overlap with fields of view of the existing and developed facilities for studying the upper atmosphere (Figure 1). It can be seen that all-sky cameras and Fabry-Perot interferometers located in GPhO will in fact observe the total volume of the atmosphere with the Incoherent Scatter (IS) Radar, Mesostratospheric (MS) Lidar, ionosondes, and receivers of Global Navigation Satellite Systems. Let us explore in a little more detail the possibility of studying some geophysical phenomena responsible for space weather or depending on it, using optical instruments together with other NHC instruments.

Geomagnetic storms are the most important geophysical phenomena of solar origin, which generate various disturbances in Earth's atmosphere. Behavior of the upper atmosphere emission during geomagnetic disturbances has been studied quite extensively (see, e.g., [Shiokawa et al., 2005]). During geomagnetic disturbances at middle latitudes, the intensity of atomic oxygen emission, mainly in the $630 \mathrm{~nm}$ line, is enhanced; strong geomagnetic storms $\left(K_{\mathrm{p}} \geq 8 \div 9\right.$, Dst $\left.<-200\right)$ are often accompanied by an enhancement of the $557.7 \mathrm{~nm}$ emission. Since the airglow in different lines is excited at different heights, using observations of the airglow spatial pattern with all-sky cameras or by monitoring the dynamics of wind and temperature with Fabry-Perot interferometers simultaneously in different spectral lines, we can obtain an overall spatial pattern of disturbance propagation, including the vertical one.

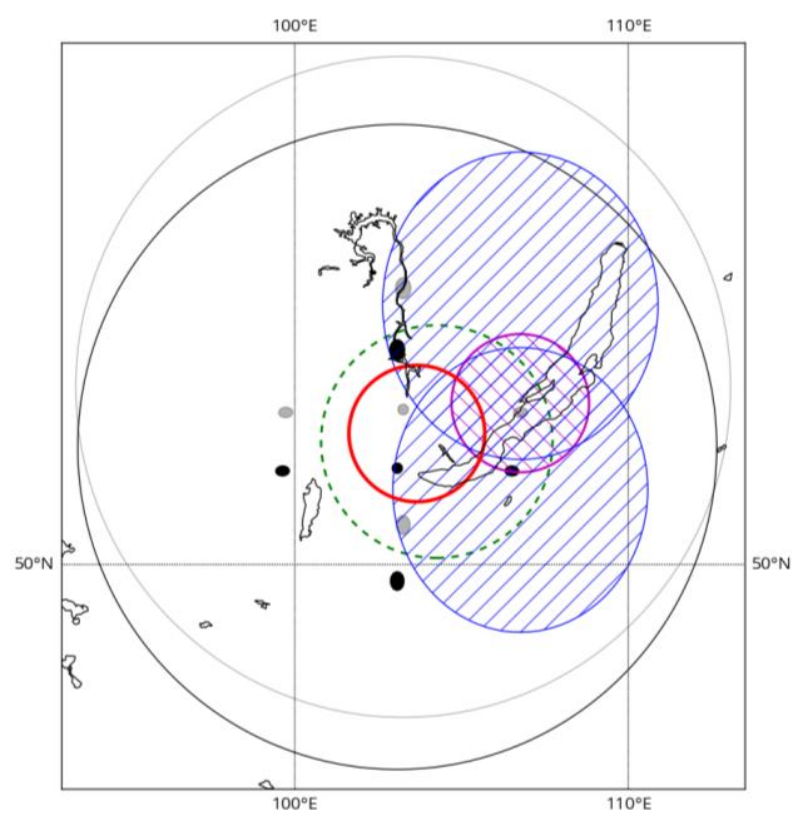

Figure 1. Projection of fields of view of NHC instruments at an altitude of $250 \mathrm{~km}$ on Earth's surface. The thick red circle indicates IKAR-AI; blue ellipses with right hatching show the IS-MST radar; the purple circle with left hatching is the MS lidar; the dotted green circle is the existing ionosonde DPS-4; the black circle marks all-sky cameras, solid black ellipses indicate a Fabry-Perot interferometer at GPhO; the gray circle is an all-sky camera, gray ellipses is a FabryPerot interferometer taken from the observatory for stereoscopic optical observations 
Using radiophysical facilities for these observations will enable us to determine the behavior of the charged component of the upper atmosphere. Currently available magnetometer stations with new multi-channel photometers can explore fast, second, and subsecond features of the processes generally related to the dynamics of particles precipitating from radiation belts. These comprehensive studies will enable us to determine the degree of interaction between charged and neutral components of the upper atmosphere, features of physicochemical processes occurring in the mid-latitude upper atmosphere during geomagnetic storms.

The stratospheric dynamics, as well as geomagnetic storms, has a significant effect on processes in the upper atmosphere. Winter sudden stratospheric warming (SSW) events occurring almost every year - spontaneous disturbances of the stratospheric circulation, which in the winter hemisphere are followed by a considerable, up to several tens of Kelvin, increase in the stratospheric temperature - generate additional wave energy in the atmosphere, alter propagation conditions of waves of different scales [Pedatella et al., 2018]. This causes a change in the wind and temperature regime of the mesosphere and lower thermosphere. As in the case of geomagnetic storms, the study of thermodynamic characteristics of the upper atmosphere, the spatial pattern of airglow in different spectral lines (hydroxyl, sodium, atomic oxygen), and dynamics of the charged component with radiophysical facilities during SSW will allow for construction of the overall spatial pattern of the upper atmosphere dynamics. Since wave processes play a crucial role in the SSW dynamics, wide-angle all-sky cameras operating in different spectral ranges will allow us to explore the vertical dynamics of wave structures in the mesosphere and lower thermosphere. In these studies, the MS lidar of NHC also plays a quite important role because only instruments of this type are capable of studying vertical profiles of parameters of the upper stratosphere (an altitude range $50-80 \mathrm{~km}$ ).

Tropospheric processes and the interaction between the ocean and the atmosphere manifest themselves in optical airglow variations on time scales ranging from microseconds (thunderstorm activity and high-altitude lightning discharges) to several years (quasi-biennial oscillations (QBO) of the equatorial zonal wind, El Niño Southern Oscillation (ENSO). Fast optical phenomena in the upper atmosphere associated with atmospheric electricity, their dynamics and morphology can readily be studied using fast photometers and all-sky cameras. The most efficient detection of high-altitude lightning discharges will be made using simultaneously optical and radiophysical instruments. The currently available systems such as WWLN, VAISALLA, thunderstorm detection network of FGUP Aerial Forest Fire Center; VereyaMP, IKFIA thunderstorm detection network, etc. provide information on coordinates of areas with thunderstorms. Using this information, all-sky cameras will allow us to assess the presence of clouds and morphologically detect the presence of high-altitude lightning discharges, and fast photometers provide information on the dynamics of the intensity of the detected airglow. The possibility of real-time control of NHC photometers, which makes it possible to change the direction of detection depending on the position of an area with thunderstorm, will greatly enhance the effectiveness of such observations. Continuing observations of the main emission lines together with previously accumulated data on the emission intensity will allow for the study of slow variations and trends of physicochemical parameters of the upper atmosphere under the action of slow variations in the tropospheric circulation. In addition, comparison of the obtained information on long-term variations in the airglow intensity with changes in gas and aerosol composition of the troposphere will allow us to understand the degree of influence of these factors on the upper atmosphere, to identify features of the vertical transport of different atmospheric components.

In the 1970-80s for the central Asian seismic zone, characteristics of the night airglow in the 557.7 and 630 nm oxygen [OI], $589.3 \mathrm{~nm}$ sodium $\mathrm{Na}$ emissions, and hydroxyl bands $\mathrm{OH}$ (8-3) were analyzed in terms of seismic activity. It was shown that during preparation and development of earthquakes in the said emissions there are disturbances of different time scales (see, e.g., [Toroshelidze, Fishkova, 1988]). Later, a similar manifestation of seismic activity in the upper atmosphere emission was revealed in the Baikal Rift Zone [Mikhalev et al., 2001; Mikhalev, 2016]. All-sky cameras, Fabry-Perot interferometers, and diffraction spectrometers will give a more complete picture of the processes that relate the lithosphere to the upper atmosphere. In addition to the intensity of emission of the main lines in the upper atmosphere, it will be quite interesting to look at the change in the temperature and wind dynamics, picture of wave disturbances, dynamics of small airglow components. Multi-spectral observations, as in the case with geomagnetic storms and SSW, will allow us to determine the nature of the vertical dynamics of these phenomena.

Meteors are phenomena observed every clear night, therefore they can be regarded as a method for longterm, continuous monitoring of the state of Earth's atmosphere. Stereoscopic or basic observations allow for measurements of the height of meteor burning up and the study of the atmospheric density dependence on height as a response to solar activity or internal causes of an increase in the atmospheric depth. This method can be used to determine the character of normalization of parameters of its outer layers after removing the external influence. As far back as the past century, observations of the drift of meteor trails indicated the presence of fast horizontal air currents in the area of their origin $(80-110 \mathrm{~km}$ ) reaching up to $300 \mathrm{~m} / \mathrm{s}$ (on average 50-70 m/s). Astapovich [Astapovich, 1958] by examining 119 meteor trails has found that during the day the drift vector is sunward. This suggested the existence of periodic movements of air masses of the upper atmosphere and corresponded to solar-diurnal geomagnetic variations due to movement of discharges in the $\mathrm{E}$ layer [Chapman, 1940; Nwankwo et al., 2018]. At the height 
of the conventional $\mathrm{E}$ layer, the sporadic layer $\mathrm{E}_{\mathrm{s}}$ often appears, which is mainly attributed to meteor activity [Martynenko, 1967; Ma et. al., 2019] or wind shear [Fabre et al., 2018]. The rate of dissipation of meteor trails is related to the pressure and temperature of surrounding air layers and can be used to estimate them [VorontsovVelyaminov, 1969; Oppenheim, Dimant, 2014]. The interaction between meteor particles and Earth's atmosphere has been studied to date only in relation to ablation of meteoroids in their passage through air layers. The question about the impact of cosmic dust influx on the upper atmosphere is still open. The influx of the meteoric matter into the rarefied upper atmosphere can significantly alter its chemical composition, particularly in terms of heavy elements. Regular observations allow for the study of the relationship between chemical composition changes and meteor showers. There are some papers that demonstrate an enhancement of the atmospheric emission in lines of different elements during strong meteor showers [Shefov et al., 2006]. Also it stands to reason that the chemical composition of particles of individual fluxes is identical, and hence different fluxes may predominantly contribute strictly defined elements [Babadzhanov, Obrubov, 1991; Rudawska et al., 2020]. At the height at which meteors burn up, one more unique and still unexplained natural phenomenon occurs - noctilucent clouds. A number of hypotheses about the origin of this phenomenon do not allow firm conclusions to be drawn about its nature. There is a meteoric hypothesis by which meteoric particles coming from outer space to the upper atmosphere become nuclei of condensation. Regular observations of meteor showers and noctilucent clouds will answer the question about their relationship. Thus, the integrated optical and radiophysical observations of meteors, which accompany the occurrence of the clouds in the upper atmosphere, and background parameters with NHC instruments will provide new information on the nature of meteor phenomena, clarify assumptions about formation of sporadic charged layers and noctilucent clouds.

When studying airglow, it is necessary to take into account the spectral transparency of the atmosphere and other elements of astroclimate and optical weather. Theoretical issues of radiation propagation in Earth's atmosphere in terms of airglow have been extensively discussed in the literature. For example, Gavrilova [1987] has theoretically solved the problem of diffuse radiation transmission in the atmosphere from a spherical luminous layer in terms to 557.7 and $630.0 \mathrm{~nm}$ oxygen emissions. A conclusion has been made that emission intensities of upper layers obtained under different atmosphere transparency differ drastically, and for proper consideration of atmospheric attenuation it is necessary to measure the atmosphere transparency simultaneously with the airglow intensity. The existence of aerosol at different heights of the atmosphere can affect the spectral distribution of twilight and night airglow due to the continuous background depending on atmospheric conditions and resulting from multiply scattered solar radiation. In case of identification of the continuous spectrum of airglow, it is reasonable to consider the component of continuous background by taking into account the dynamics of aerosol structures and optical characteristics of the lower atmosphere [Mikhalev, Tashchilin, 2007]. Radiation characteristics of aerosol in GPhO have been studied in the monograph [Research ..., 2012]. The sun photometer CIMEL-318, which is part of the ground-based network of stations AERONET, was used to study the seasonal variability of aerosol optical thickness (AOT) and atmospheric moisture content: seasonal variations, annual and diurnal variations of spectral AOT. Mikhalev et al. [2019] using previously obtained spectral characteristics of AOT and atmospheric moisture content have analyzed the effect of atmospheric aerosol on ground observations of the airglow in the 557.7 and $630.0 \mathrm{~nm}[\mathrm{OI}]$ atomic oxygen emission lines. They observed a spectral dependence of correlation coefficients between intensities of the $557.7,630.0 \mathrm{~nm}$ emissions and AOT, and revealed its non-linear character: an increase in the correlation coefficients at small values of AOT (0.5) and their decrease at large ones. It should be emphasized that in both the works the atmosphere transparency data was obtained with a sun photometer and, in general, may not reflect the dynamics of aerosol at sunset-to-sunrise time. Multi-spectral optical and lidar observations with the NHC new instruments will enable us to examine the seasonal variability of spectral AOT at night and to monitor airglow corrected for atmosphere transparency under any conditions of optical weather.

Besides observing the processes occurring in Earth's atmosphere under the action of natural factors, methods of active influence on the upper atmosphere in order to study it are widely used. The presence of Earth's ionosphere and the development of a powerful short-wave transmission technique allow for such influence through heating of ionospheric electrons by powerful radio waves in a range 1-10 $\mathrm{MHz}$. Under $\mathrm{NHC}$, a heating facility IKAR-AI (Irkutsk Short-Wave Array of Active Transmitters) is being developed. It works in a range $2.5-6.0 \mathrm{MHz}$ with an effective radiated power of $\sim 200 \mathrm{MW}$. It is well known that under the action of powerful radio waves in the ionosphere electrons are accelerated to superthermal energies and due to shock excitation of atomic oxygen a region irradiated by powerful radio waves begins to glow [Biondi et al., 1970; Bernhardt et al., 2000]. Airglow parameters, its height, intensity, and form depend greatly on electron acceleration conditions, hence the use of spaced all-sky cameras operating in different spectral ranges will enable stereoscopic methods to determine characteristics of the glowing region, and the use of twobeam interferometry with the NHC IS radar will allow us to compare the size of small-scale structures observed by optical and radiophysics methods. Monitoring the temperature dynamics of the modified region with FabryPerot interferometers and the IS radar will enable us to independently compare the behavior of temperature of the neutral and charged components of the upper atmosphere under artificial influence. Thus, the integrated optical and radiophysical studies of the upper atmosphere with NHC will provide new insights into the processes occurring in ionospheric plasma and will clarify their 
details. In addition to studies of the region with modified ionosphere, IKAR-AI and NHC instruments will allow for the study of artificially generated natural processes such as internal gravity waves and particle precipitation. The spatial pattern of evolution of these phenomena derived from optical observations in different spectral ranges, monitoring of the atmospheric circulation and temperature provide NHC with a unique opportunity to study their vertical dynamics in various virtually controlled conditions.

In addition to the ionosphere modification by powerful radio waves, the presence of rocket and space equipment and orbital satellite systems will allow for a direct physicochemical modification of the upper atmosphere. Energy of the modification can vary widely from multi-kilogram hot supersonic fuel emissions of cruise engines of spacecraft to injection of nearly a kilogram of chemically active substances. Such a modification in the upper atmosphere depending on the intensity and type of ejected substance leads eventually to a modification in the chemical and ionic composition of the upper atmosphere, generation of acoustic and infrasound internal gravity waves and, consequently, gives rise to glowing structures. The use of the complex of optical instruments of NHC in this case will allow us to identify features of chemicophysical processes. Temperature and dynamic regimes of the upper atmosphere as well as their variations will be determined with Fabry-Perot interferometers. Spaced all-sky cameras will determine the height of glowing structures; diffraction spectrometers provide information both on the behavior of natural atmospheric optical emissions and on artificially injected substances. As with meteors, the question about the influence of fragments of satellites, which break up in the upper atmosphere and usually contain chemically active components, on the upper atmosphere remains open. Ground-based systems such as the complex of optical instruments developed as part of NHC will help to assess the degree of impact of human activity on near-Earth space, especially in view of recent events related to the start of earth orbit launch of the large-scale telecommunication satellite constellations OneWeb, Starlink, and to determine the chemicophysical nature of the changes.

\section{CONFIGURATION OF OPTICAL INSTRUMENTS AND SOME RESULTS}

Since the airglow spectrum consists of lines and bands of emission of atoms and molecules of gas components, the main characteristics observed are the temporal dynamics of intensity and parameters of individual spectral components. Intensities of spectral lines are observed with spectrometers of different types - diffraction, prism, etc. A spectral pattern in these instruments is recorded with special-purpose high-sensitivity CCD matrices considerably simplifying and automating recording, storage, and processing of spectrograms. At present, GPhO uses spectrometers of this type with spectral resolution from $10 \mathrm{~nm}$ to $0.2 \mathrm{~nm}$, capable of covering the 300-700 $\mathrm{nm}$ range, and time resolution 110 min. A diffraction infrared spectrometer (operating spectral region 800-900 nm) with a high-sensitive cooled digital receiver is employed to obtain spectral characteristics (intensity, temperature) of emissions of hydroxyl molecules (6-2 band, $834.0 \mathrm{~nm}$, a height of maximum emission is $\sim 87 \mathrm{~km}$ ), and the atmospheric system of molecular oxygen $(0-1$ band, $864.5 \mathrm{~nm}$, a height of maximum emission is $\sim 94 \mathrm{~km}$ ). The measurements have been made in a patrol mode since 2008. These spectra are used to calculate the rotational hydroxyl temperature, which corresponds to the atmospheric temperature at heights of the emitting layer (mesopause region). The intensity of atmospheric emissions of $\mathrm{OH}$ and $\mathrm{O}_{2}$ molecules provides information on dynamic processes in the emitting layer, as well as on concentration of the main atmospheric components. Ground-based spectral measurements are used to monitor the temperature regime of the upper atmosphere, to study effects of heliogeophysical impacts of various nature, wave processes in the upper atmosphere, effects of winter SSW, long-term trends in temperature, satellite data validation, influence of solar and geomagnetic activity on the state of the upper atmosphere [Medvedeva, Ratovsky, 2015, 2019; Medvedeva et al., 2019].

Diffraction and prism spectrometers of visible range with cooled photosensors monitor the temporal dynamics of the intensity of 557.7 and $630.0 \mathrm{~nm}$ atomic oxygen and 589.0, $589.6 \mathrm{~nm}$ sodium doublet lines with temporal resolution of several minutes. Oxygen emissions are utilized to study the mesosphere - lower thermosphere dynamics during geomagnetic storms, winter SSW, influence of solar activity, and other phenomena [Mikhalev, 2011] because a spontaneous emission height of these lines is $\sim 250 \mathrm{~km}(630.0 \mathrm{~nm})$ and $\sim 100 \mathrm{~km}(557.7 \mathrm{~nm})$. The sodium doublet glow is used to study meteor showers [Komarova, Mikhalev, 2014].

Characteristics of the lines recorded provide information about motion of a glowing substance. From monochromatic radiation of atoms and molecules, we can observed the Doppler effect, which leads to a broadening and shift of spectral lines due to chaotic (temperature) and collective (drift, wind) motions of atoms and molecules. Fabry-Perot interferometers can form an interference pattern sensitive to the shift and broadening of the spectral lines at $10^{-15}-10^{-14} \mathrm{~m}$. Such variations in the Doppler broadening and shift of lines occur during variations in the wind of order of several meters per second and in the temperature of the order of several Kelvin. GPhO is equipped with a Fabry-Perot interferometer adapted for aerodynamic research and equipped with a thermally-stabilized etalon 70 $\mathrm{mm}$ in diameter, input interference filters, and a highly sensitive CCD camera with a cooled photosensor [Shiokawa et al., 2012]. Wind and temperature dynamics of the upper atmosphere for several spectral lines is recorded by the interferometer with time resolution of $\sim 10$ minutes. This information is extremely useful for the study of both its regular variations and geophysical events of different types, magnetic storms, SSW, etc. [Vasilyev et al., 2017, 2018; Mikhalev et al., 2018]. 
In addition to spectrometers, glow of certain lines can be detected using single-channel photometers with interference filters with transmission peak near a wavelength of interest. The main advantage of the photometers with interference filters is their high focal ratio. This provides high time resolution (on the order of milliseconds). They can therefore be used to explore features of meteor glow, lightning flashes, rapid variations in the glow of the mesosphere and thermosphere. A multichannel photometer operated at GPhO until 2010 [Beletsky et al., 2010] and was taken out of service because of the modernization of equipment. As of now, the observatory has no photometric instruments of this type. Rapid glow variations at $\mathrm{GPhO}$ are detected with devices based on CCD matrices, which can identify observed rapid events from their images, but time resolution comparable to that of devices based on photomultipliers has not been attained yet [Tkachev et al., 2017, 2019].

Detection of spatial variations in night airglow and control of the atmosphere transparency are performed directly above the point of observation of color CCD cameras. A special-purpose wide-angle optical system installed in GPhO in 2013 having, like the photometer, interference bandpass filters, provides the spatial pattern of the $630.0 \mathrm{~nm}$ atomic oxygen line intensity. GPhO periodically detects the spatial pattern of 557.7 $\mathrm{nm}$ atomic oxygen glow and hydroxyl glow. The use of wide-angle cameras in the selected spectral lines and bands has shown their high efficiency. The observations are used to study mid-latitude airglows such as subauroral red arcs (SAR-arcs), internal gravity waves, long-lived meteor trails, and artificial airglow excited by a heating facility and in active space experiments [Tashchilin et al., 2010; Beletsky et al., 2016; Mikhalev et al., 2018; Shindin et al., 2018].

Several instruments (all-sky camera KEO-Sentinel, Fabry-Perot interferometer KEO-Ari-nae, diffraction spectrometer Shamrock-i303) have been put into operation at GPhO relatively recently. These instruments are in fact prototypes of the equipment used to develop the complex of optical instruments as part of NHC. Below are some results obtained with these prototypes, which demonstrate the efficiency and feasibility of the equipment selected for NHC and can be utilized as the groundwork for follow-up studies.

\section{VERTICAL WIND}

It is extremely important to understand processes of the vertical atmosphere dynamics in order to study the influence of geomagnetic disturbances on the atmosphere, interaction between the processes at various altitude levels, which occur in the atmosphere itself, or the influence of the lithosphere and ocean on the state of Earth's atmosphere. In this regard, the vertical wind, or vertical drift of air masses, which transfers energy of air motion to different altitude levels and allows for vertical transport of chemical components as effectively as possible may be considered the most significant. Clearly the integral vertical motion of air at large spatial and temporal scales is insignificant, but uneven heating of different regions of the atmosphere in combination with horizontal (advective) transport of heat hypothetically may lead to the formation of local regions with pronounced vertical motion. This vertical air motion occurs due to convection processes in the near-surface layer of the atmosphere or in tropospheric circulation cells (Hadley cell, Ferrel cell, polar cell). Recent findings on vertical air transport in the middle thermosphere acquired with prototypes of the instruments, included in the NHC optical complex, and radiophysical instruments [Medvedev et al., 2019] suggests the possible existence of a vertical circulation cell regularly moving from the pole to the equator and back within 24 hours. This is illustrated in Figure 2, which shows the dynamics of vertical and meridional neutral winds averaged over geophysical winter ( \pm 45 days from winter solstice), which was obtained with a Fabry-Perot interferometer using the method described in [Vasilyev et al., 2017], and the dynamics of the F2-layer peak height obtained with an ionosonde. The height of the maximum electron density varies under the action of the neutral wind. What's interesting is that these variations are generally attributed to the meridional wind, which causes magnetized plasma to move along the geomagnetic field lines inclined from the vertical (Figure 3). The presence of the vertical neutral wind for the geometry in which the direction of the geomagnetic field vector is closer to the vertical than to the horizontal, however, brings about a more pronounced effect of the vertical wind on the height of the maximum electron density. Using information about the position of the magnetic field vector and both neutral wind speeds, we can, by analogy with the servo model [Rishbeth, 1967], model the dynamics of the drift of the maximum electron density as

$$
\begin{aligned}
& H_{\mathrm{m}} \mathrm{F}^{\prime}(t)=z_{0}+c D(t)= \\
& =z_{0}+c\left[V(t) \sin \alpha \cos \alpha+W(t) \cos ^{2} \alpha\right],
\end{aligned}
$$

where $H_{\mathrm{m}} \mathrm{F} 2^{\prime}$ is the position of the maximum electron density; $z_{0}$ is the balance height of the electron density peak, determined by diffusion and recombination of night ionospheric plasma in the absence of drift due to the neutral wind; $V$ is the velocity of the meridional neutral wind; $W$ is the speed of the vertical neutral wind; $\alpha$ is the angle between the inclination of the geomagnetic field and the vertical (assuming that the magnetic field is oriented strictly along the north-south line, which with high accuracy holds for the place where these studies of the vertical wind were carried out); $D$ is the projection of the total neutral wind speed on the geomagnetic field vector; $c$ is the scale factor describing the degree of interaction between charged and neutral components, as well as the relationship between the velocity of vertical drift of the charged component and the height of the peak electron density. As we can see, the behavior of $H_{\mathrm{m}} \mathrm{F} 2$ for $z_{0}=300 \mathrm{~km}$ and $c=1$ agrees fairly well with the actually observed behavior of the F2-layer maximum (Figure 2, right).

It is clearly seen that the maximum height of the peak electron density is observed in the middle of the night when the upward vertical wind is maximum. A decrease in the F2-layer peak height during hours close to sunrise and sunset occurs with an increase in the downward vertical wind. Coefficients of the correlation 

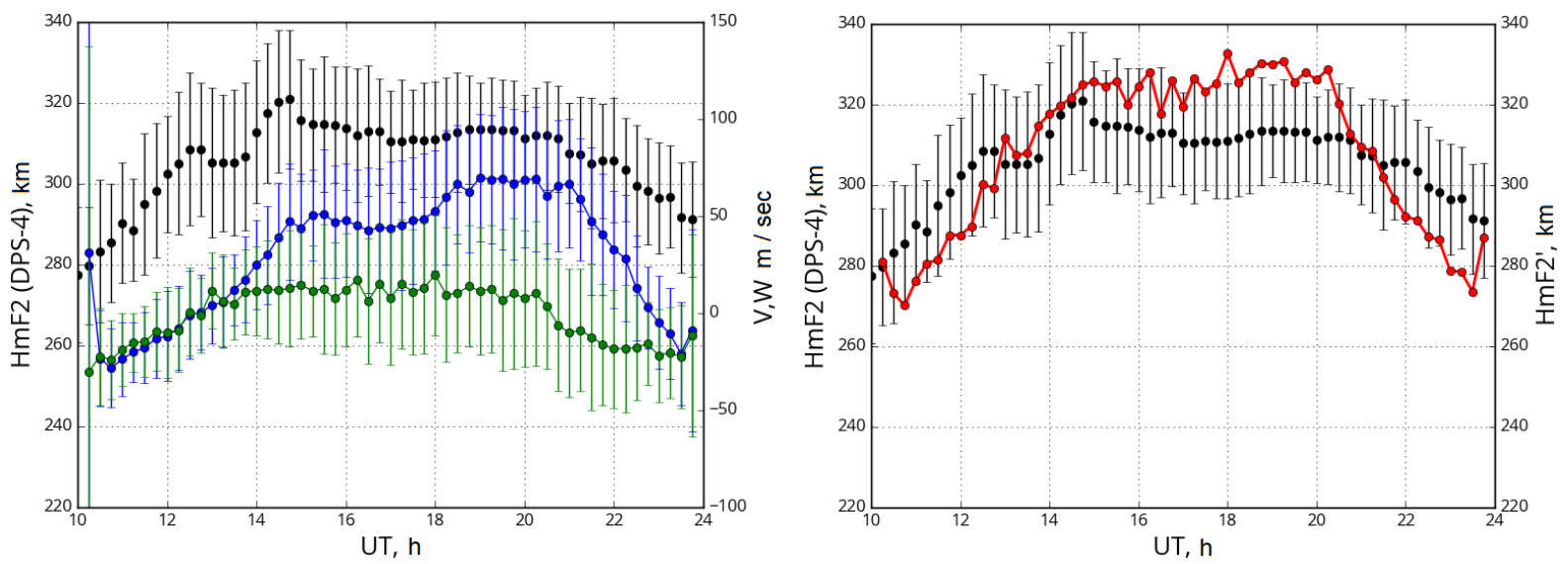

Figure 2. Left - the behavior of the F2-layer peak height (black), of the meridional wind (blue, positive southward direction), of the vertical wind (green, positive upward direction) averaged over a certain time UT during geophysical winter ( \pm 45 days from the winter solstice). Right - comparison between the F2-layer peak height obtained from (1) (red) and that measured with an ionosonde (black)

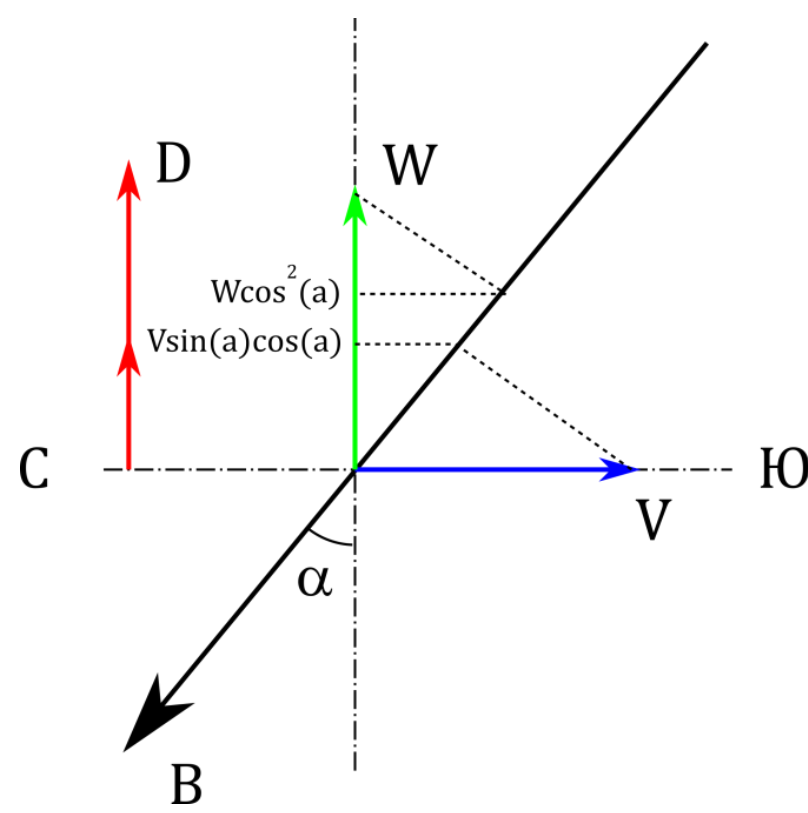

Figure 3. Effect of the neutral wind on magnetized plasma. $\mathbf{V}, \mathbf{W}$ are the directions of the meridional and vertical winds respectively, $\mathbf{B}$ is the direction of the geomagnetic field vector, $\mathbf{D}$ is the plasma vertical drift under the combined action of the meridional and vertical winds (1); N, S are the cardinal directions

of different wind components and the calculated drift with the position of the F2-layer maximum are listed in Table 1. If the contribution to the vertical motion of the charged components depends exclusively on the meridional wind, the correlation coefficient between $H_{\mathrm{m}} \mathrm{F} 2$ and the meridional wind should be maximum. The correlation coefficient between the vertical wind and $H_{\mathrm{m}} \mathrm{F} 2$ is, however, higher. This means that the vertical wind gives a greater contribution to the F2-layer maximum because the direction of the geomagnetic field is close to vertical at the point of observation (Figure 3). Moreover, the behavior of the F2-layer maximum estimated using (1) has a maximum correlation coefficient if a combination of meridional and vertical winds is utilized, with the tendency continuing for three seasons.
Hence, we can conclude that the vertical wind variation observed by a Fabry-Perot interferometer at an altitude of $\sim 250 \mathrm{~km}$ from the $630 \mathrm{~nm}$ atomic oxygen line emission is generated just by vertical motions in the middle thermosphere.

The observed diurnal variations of the vertical wind can be explained by the presence of a circulating cell, which is situated at the height of the middle thermosphere, is elongated along the meridian, and moves during the day from the pole to the equator and back.

To obtain compelling evidence for (or against) the presence of this circulation structure, it is necessary to make two-position stereoscopic observations of the dynamics of the full vector of the neutral wind speed. This will be facilitated by the new optical equipment of NHC, which is installed in the Geophysical Observatory, located to the north of the complex of optical instruments of NHC (see Figure 1). These observations necessarily require time synchronization, which will be provided by devices forming time marks from signals of global navigation satellite systems.

The diurnal-seasonal dynamics of the vertical wind for 2017-2020 at various altitude levels (630.0 and $557.7 \mathrm{~nm}$ atomic oxygen lines) is illustrated in Figure 4. An essential point is the difference in the behavior of the vertical wind for the heights of $\sim 250 \mathrm{~km}(630 \mathrm{~nm}$ atomic oxygen line) and $\sim 100 \mathrm{~km}(557.7 \mathrm{~nm}$ atomic oxygen line). We can see that in the middle thermosphere in winter there is a regular diurnal variation of the vertical wind velocity with direction changing in the evening and in the morning, whereas in the lower thermosphere there is no pronounced diurnal variation, but there is a clear-cut annual variation of the wind velocity with direction changing in summer and winter.

The Fabry-Perot interferometer during observation successively changes color filters corresponding to different atomic oxygen lines, i.e. we can say that parameters of red and green emission lines are observed simultaneously within a ten-minute interval, using a single method. Thermal stabilization of the Fabry-Perot interferometer to eliminate the temperature dependence of observations is performed in two stages: by hardware using a dedicated thermostabilizing system, and then 
Table 1

Correlation coefficients for observed wind velocities and $H_{\mathrm{m}} \mathrm{F} 2$ (synchronously, from averaged values within a season)

\begin{tabular}{|l|c|c|c|}
\hline \multicolumn{1}{|c|}{$\begin{array}{c}\text { Pearson correlation coefficients } \\
\text { for }\end{array}$} & $\begin{array}{c}\text { Geophysical winter } \\
\text { 2016-2017 }\end{array}$ & $\begin{array}{c}\text { Geophysical winter } \\
\text { 2017-2018 }\end{array}$ & $\begin{array}{c}\text { Geophysical winter } \\
\text { 2018-2019 }\end{array}$ \\
\hline Vertical wind and $H_{\mathrm{m}} \mathrm{F} 2$ & 0.905 & 0.885 & 0.918 \\
\hline Meridional wind and $H_{\mathrm{m}} \mathrm{F} 2$ & 0.825 & 0.795 & 0.878 \\
\hline $\begin{array}{l}H_{\mathrm{m}} \mathrm{F} 2 \text { derived from DPS-4 data } \\
\text { and from }(1)\end{array}$ & 0.953 & 0.921 & 0.961 \\
\hline
\end{tabular}
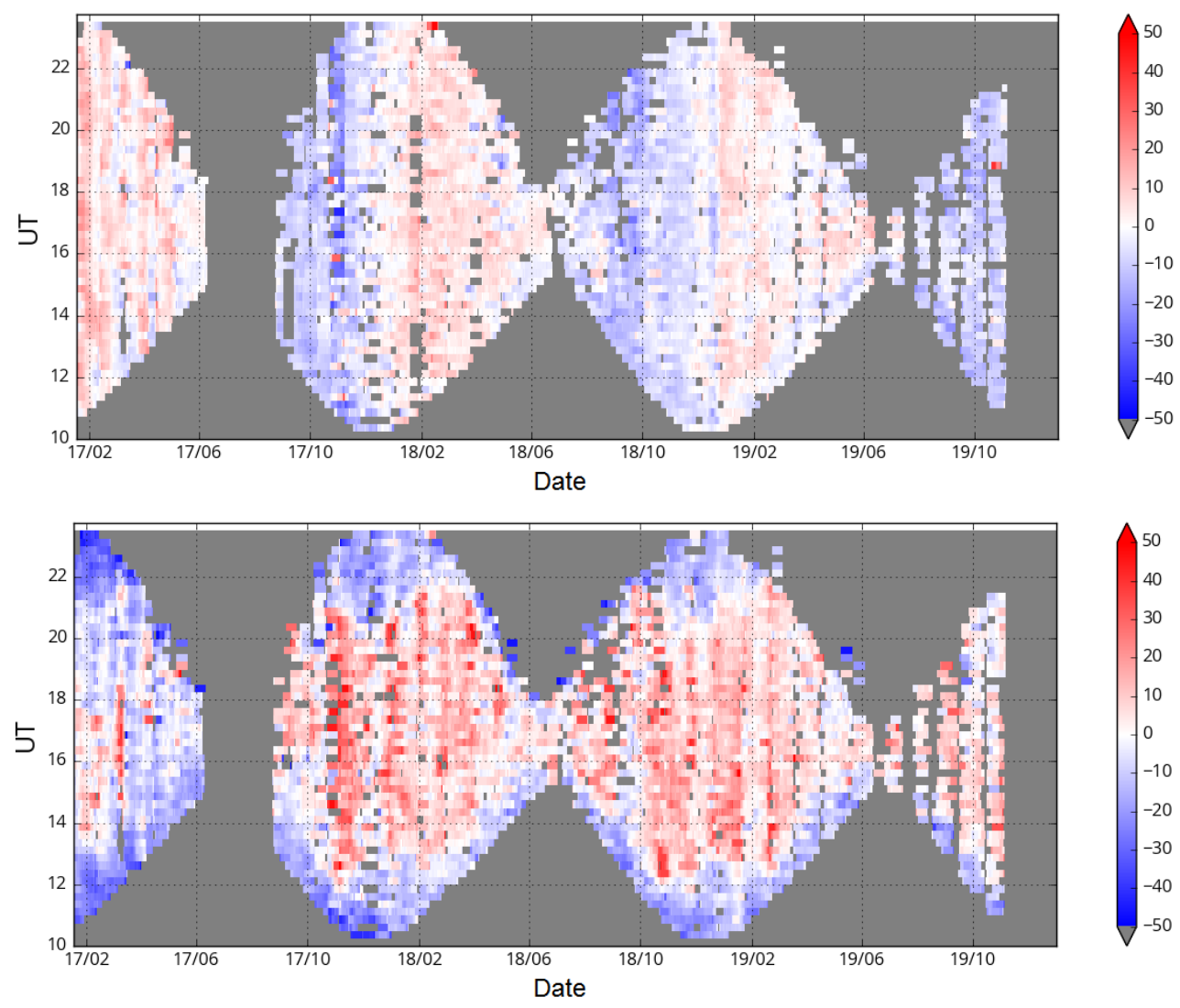

Figure 4. Interannual, diurnal-seasonal behavior of the vertical wind observed from two different atomic oxygen emission lines. The horizontal axis is the date, the vertical axis is the universal time, color shows the wind speed in $\mathrm{m} / \mathrm{s}$. At the top - the behavior of the wind speed obtained in the $557.7 \mathrm{~nm}$ line $(\sim 100 \mathrm{~km})$; at the bottom - the behavior of the wind speed obtained in the $630.0 \mathrm{~nm}$ line $(\sim 250 \mathrm{~km})$

during processing of raw data using information on the hardware function of the device, obtained with a frequency-stabilized helium-neon laser. The methods of processing raw data (interferograms) for each line to obtain the wind velocity are identical. There is most likely no hardware effect on data or environmental effects (scattering in the troposphere, surface temperature variations, etc.) due to the fact that the behavior of the wind differs at different heights (see Figure 4). Thus, the observed difference in the vertical wind dynamics suggests various phenomena that lead to its occurrence, for example, we may suppose that there are two independent circulation cells in the middle and lower thermosphere. Ascertaining this fact (identification of parameters of the circulation cells) is one of the most interesting scientific problems to solve with NHC.

\section{STEREOSCOPIC OBSERVATIONS WITH ALL-SKY CAMERAS}

As has been mentioned, the presence of several (at least two) cameras observing completely or partially overlapping region of the upper atmosphere will allow for stereoscopic observations of glowing structures. This information will help to reconstruct not only the height but also the full three-dimensional picture of the structure. An example would be relatively recent stereoscopic observations of a long-lived meteor trail [Ivanov et al., 2019]. It was observed in November 2017 and was simultaneously detected by two all-sky cameras spaced at a distance of $150 \mathrm{~km}$. Due to the fact that stereovision is based on triangulation of corresponding pixels in two images, there must be an exact correspondence between the position of a pixel in the camera 
coordinate system and the world coordinate system [Borovička et al., 1995]. Furthermore, for wide-angle cameras aberrations of optical systems that can significantly affect the determination of coordinates are inevitable. To eliminate these distortions in images, calibration has been made which allows us to compare the position of pixel of a photosensitive matrix with a given coordinate in the celestial sphere. The calibration was made against the position of observable stars. From the calibration we have derived analytical dependences that take into account radial distortions and relationships between coordinate systems for each camera:

$$
\begin{aligned}
& \theta=-1.024 \cdot 10^{-4}\left[\left(x-x_{0}\right)^{2}+\left(y-y_{0}\right)^{2}\right]- \\
& -0.2701 \sqrt{\left(x-x_{0}\right)^{2}+\left(y-y_{0}\right)^{2}}+88.87, \\
& \varphi=\tan ^{-1}\left[\frac{\left(y-y_{0}\right)}{\left(x-x_{0}\right)}\right],
\end{aligned}
$$

where $\theta$ is the elevation angle; $\varphi$ is the azimuth; $x, y$ are the coordinates in the frame (pixel number along the horizontal and the vertical); $x_{0}, y_{0}$ are the zenith point coordinates. Using these expressions for each pixel of the matrix, by solving the geodesic problem we can find geographical coordinates of the image projection from a certain altitude to Earth's surface. The next step was to compare projections of meteor trail images from a fixed altitude, obtained simultaneously at different observation points (Figure 5). If the geographical coordinates of any part of the meteor trail in one image coincide with the coordinates of any part of the meteor trail in the second one, we can say that this part of the trail is at the altitude for which the image projections were made. Next, for each close moment of observation of the trail, its images were constructed in geographic coordinates at two observation points for a set of altitudes, and overlapping parts of the trail were found for each altitude.

This may yield three-dimensional dynamics of the entire trail in time. The three-dimensional coordinates of the meteor trail for images from cameras in Figure 5 are listed in Table 2. For selected points 1-4, altitudes are the same, hence we can state that this part of the meteor trail propagated mainly horizontally at an altitude of $\sim 73 \mathrm{~km}$. Coincidences for other parts of the trail in the projections were found above $\sim 105 \mathrm{~km}$.

Table 2

Coordinates of a long-lived meteor trail, reconstructed using data from Figure 5

\begin{tabular}{|c|l|l|r|}
\hline Number & Latitude & Longitude & Altitude \\
\hline 1 & 51.85 & 101.70 & 73 \\
\hline 2 & 51.75 & 101.70 & 73 \\
\hline 3 & 51.50 & 101.62 & 73 \\
\hline 4 & 51.75 & 101.23 & 73 \\
\hline 5 & 52.00 & 101.00 & 80 \\
\hline 6 & 52.30 & 100.90 & 85 \\
\hline 7 & 53 & 100.5 & 105 \\
\hline
\end{tabular}

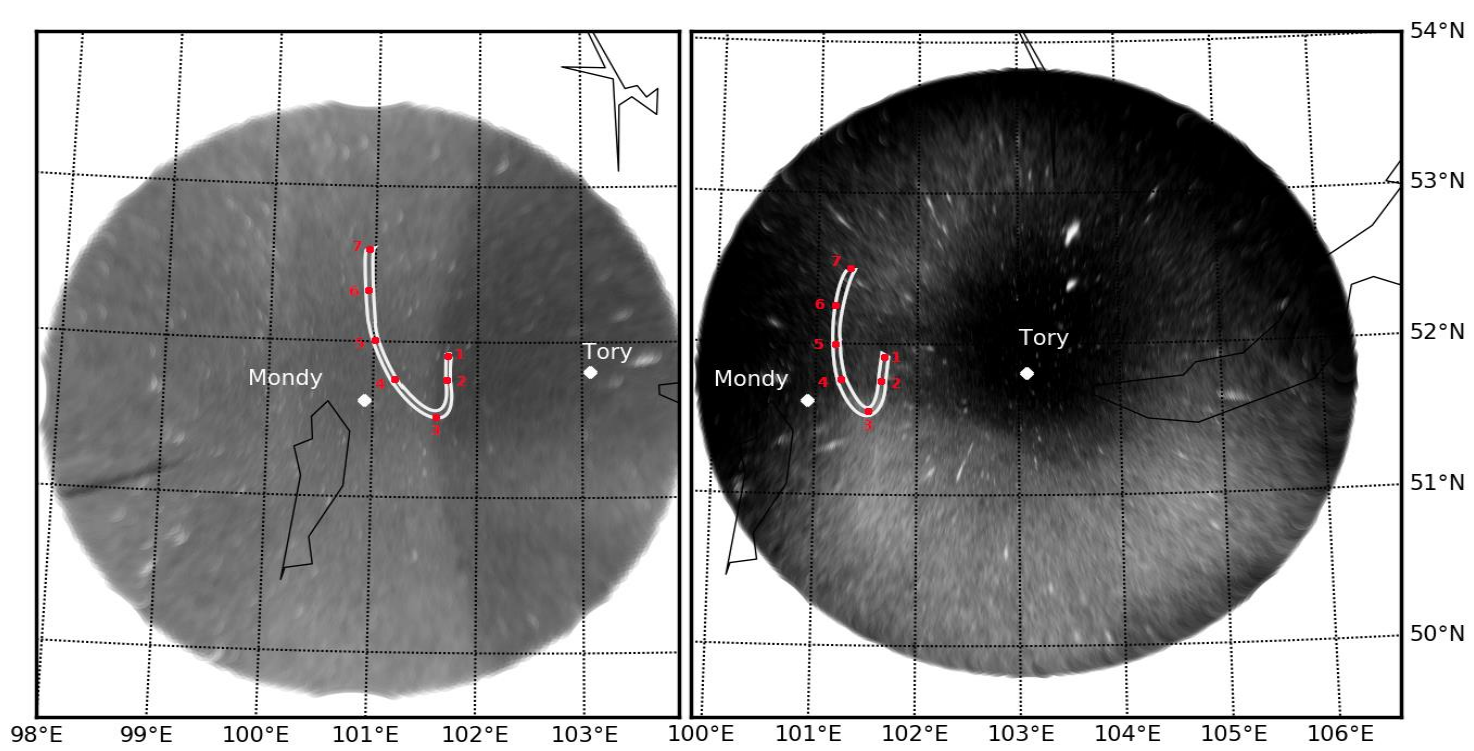

Figure 5. At the top - a series of frames with meteor trail dynamics captured by a camera in Sayan Solar Observatory (SSO). At the bottom - projections of images from two cameras (left - SSO, right — GPhO) on Earth's surface from an altitude of $73 \mathrm{~km}$. Numbered points are the meteor trail parts for projections of which on Earth's surface we have found coincidences for different altitudes 
The images with projections were processed visually by an operator as it is impossible to automate this stage because of the complex identification of the meteor trail against a background of other objects — bright stars, uneven background glow etc. The proposed method is similar to methods used by other research groups studying the upper atmosphere, e.g. [Kouahla et al., 2010]. With lidar, radar, and satellite data this method will most accurately reconstruct spatial characteristics of such events as wave structures, auroral arcs, meteor trails, artificial structures, etc. It can be assumed that the accumulated statistics of events along with the development of computer vision techniques, neural network algorithms for image processing will allow us to automate this process as in [Whiter et al., 2013] and find a use for it in other applied scientific problems.

\section{OPTICAL INSTRUMENTS IN ACTIVE EXPERIMENTS}

Active space experiments are an effective method of examining Earth's upper atmosphere as they allow us to monitor conditions and parameters of the impact on the medium under study. The prototypes of NHC optical instruments described above were used in the active space experiment Radar-Progress [Beletsky et al., 2016; Mikhalev et al., 2016] on injection of fuel of onboard engines of spacecraft in the thermosphere. In particular, it has been found that after ignition of approach-correction engines (ACE) of Progress cargo spacecraft (CS) in the thermosphere, regions of enhanced airglow are formed. It has been suggested that these glowing structures are related to scattering of twilight solar emission by products of ACE operation at the CS orbit with occurrence of additional glow in the $630 \mathrm{~nm}$ [OI] atomic oxygen emission due to the modification of the ionosphere. Approximate dynamics of such structure is shown in Figure 6.

This sequence of frames taken at $30 \mathrm{~s}$ intervals shows a spatiotemporal dynamics of a glowing structure resulting from ignition of ACE (bright spot in the middle of the frame). The maximum observed dimensions of the airglow region are $330-350 \mathrm{~km}$ along the orbit and $250-270 \mathrm{~km}$ across it. The rate of extension of the airglow region in the first moments after the ACE ignition was $6-7 \mathrm{~km} / \mathrm{s}$ along the orbit and $3-3.5 \mathrm{~km} / \mathrm{s}$ across it. The shaded area around the elongated image from the exhaust in the first frame is likely associated with the peculiarity of the special-purpose differential image processing technique developed by ISTP SB RAS [Tkachev et al., 2017, 2019] for studying such phenomena. Artifacts at edges of the frame are connected with the images of stars and the Moon unremovable in the current version of the technique.

Later, Mikhalev et al. [2020] have considered the contribution of different components of injected substance $\left(\mathrm{H}_{2}, \mathrm{OH}, \mathrm{H}_{2} \mathrm{O}, \mathrm{CO}\right.$, and $\left.\mathrm{CO}_{2}\right)$ to the enhancement of the intensity of the $630.0 \mathrm{~nm}$ [OI] atomic oxygen emission and to the change of charged components of the upper atmosphere. The changes in the emission intensity and concentration of charged components were shown to be caused by different chemical reactions.
Injection of hydrogen and carbon dioxide to the atmosphere makes the greatest contribution to the enhancement of the airglow intensity in the $630.0 \mathrm{~nm}$ emission, and the decrease in the concentration of charged components is mainly due to injection of water vapor.

Heating of the ionosphere by short-wave radio waves is a powerful tool for studying ionospheric plasma and Earth's upper atmosphere. The prototypes of NHC optical instruments were used to study glowing structures generated by the heating facility SURA.

The ionosphere was modified by HF radio waves of ordinary polarization at vertical antenna pattern of the heater. The artificial airglow was recorded at two spaced points with all-sky cameras at a wavelength of $630 \mathrm{~nm}$. One was located in the immediate vicinity of the SURA antenna system, the second was at a distance of $\sim 170 \mathrm{~km}$ from the heater. As a result, images of glowing regions were taken which allowed for the stereoscopic determination of spatial parameters of the structures and their relationship with parameters of the powerful radio wave [Shindin et al., 2018].

\section{CONCLUSION}

We have presented information about the following new optical instruments of the National Heliogeophysical Complex:

- photometers for high-speed photometry of the main emission lines of the upper atmosphere with a field of view of $\sim 10^{\circ}$ and time resolution of $1 \mathrm{~ms}$;

- diffraction spectrometers for recording the spectral composition of night airglow in visible and infrared spectral ranges, which have $\sim 0.1 \mathrm{~nm}$ spectral resolution and sensitivity sufficient to observe variations in the intensity of lines in several Rayleigh;

- wide-angle optical systems (all-sky cameras) with spatial resolution $\sim 0.1-0.5^{\circ}$, equipped with automatically interchangeable light filters for observation of the main emission lines of night airglow and sensitivity to observation of intensity variations in several Rayleigh;

- Fabry-Perot interferometers with etalon $70 \mathrm{~mm}$ in diameter, equipped with automatically interchangeable light filters for observation of the main emission lines of night airglow, an automatically controlled periscope input window having a sensitivity sufficient to detect wind and temperature variations in the upper atmosphere at a level of $5 \mathrm{~m} / \mathrm{s}$ and $5 \mathrm{~K}$ respectively.

Researchers have noted the utility and importance of the facility and the use of these instruments in combination with currently available and future NHC facilities. It is necessary to duplicate these instruments to perform simultaneous observations of atmospheric parameters in different spectral ranges corresponding to different altitude levels. The currently available prototypes of the instruments can be used to develop a local network of optical instruments for stereoscopic observations of glowing structures. Both these features make it possible to reconstruct the three-dimensional dynamic pattern of parameters of the neutral atmosphere, in combination with other instruments of the complex will allow for a detailed study of the interaction between neutral and charged components under different geophysical conditions and artificial impacts. 


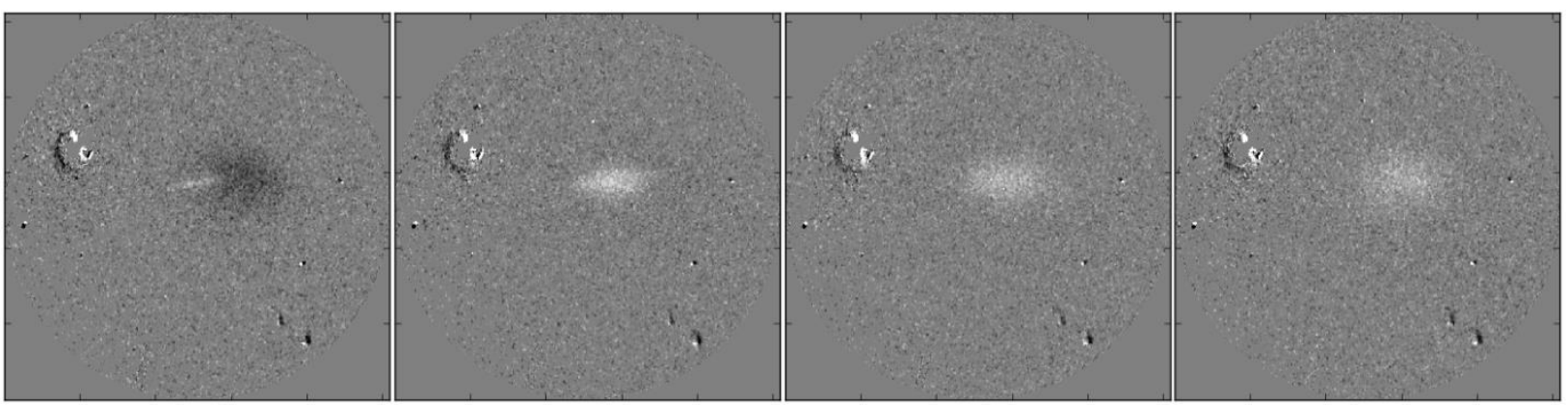

Figure 6. Sequence of frames from an all-sky camera processed using a differential method of identifying regions with fast intensity variations. The time the frames were taken (left to right): 13:24:31, 13:25:02, 13:25:33, 13:26:04 UT; the engine ignition at 13:24 UT. Glowing exhaust — the bright spot in the middle of the frame

Continuation of the long-term observations of the main emission lines and small spectral components will enable the study of long-term trends of parameters of the upper atmosphere, in particular under the action of anthropogenic factors.

Currently, the data obtained using the prototypes of the NHC optical instruments on active experiments, large magnetic storms, study of fast optical phenomena in Earth's atmosphere, etc. are taken as an experimental basis for implementation of some RFBR grants (No. 1705-00492; No. 17-29-05047; No. 18-05-00594; No.1905-00665; 20-05-00212; No. 20-05-00580) for the study and modeling of these phenomena.

Equipment of the NHC optical instruments with fast photometric instruments will provide additional capabilities for the study of atmospheric electricity, meteors, and fast variations of the natural airglow and midlatitude auroras. These sporadic events can serve as an additional source of information on the state of the upper atmosphere. Further development of methods for fast photometry of meteors can provide information on the temperature and wind dynamics in the mesosphere and stratosphere. Studying high-altitude lightning discharges is a fairly new and interesting field of research. Like meteors, parameters of high-altitude lightning discharges, their temporal and spatial dynamics have much to tell about the physicochemical state of the upper atmosphere. Furthermore, the source of high-altitude lightning discharges — tropospheric storm activity may be quite a good indicator of the degree of influence of external factors (solar and geomagnetic activities) on the state of the troposphere. Importance of this research is obvious because it is precisely the tropospheric weather events that have the greatest impact on human activity; and full-scale studies of the vertical interaction between the troposphere, stratosphere, mesosphere, and thermosphere are critical for the modernization of existing and development of new models of Earth's atmosphere.

The preliminary results of observation of the joint dynamics of the vertical wind and charged components of the upper atmosphere made with the prototypes of the NHC optical instruments and ionosonde indicate the promising outlook for further studies on specification of the mutual influence of the charged and neutral components of the upper atmosphere under different geophysical conditions and artificial effects, using both the new mid-latitude heating facility developed under NHC and satellite and rocket facilities. The vertical wind dynamics recorded by the prototypes of the NHC optical instruments for several years in different altitude levels shows that there may be closed circulation cells in the upper atmosphere, which are located in the thermosphere and exhibit substantially different behavior. To confirm the presence of the circulation cells and to determine their parameters more precisely, it is necessary not only to install additional optical instruments in $\mathrm{GPhO}$, but also to space the currently available prototypes at some distance in order to determine the full space-time dynamics of these structures, using stereoscopic methods. Moreover, to determine the large-scale structure of the circulation cells it is necessary to deploy new observation stations or to use existing Russian and foreign observation networks. Thus, one of the research objectives for NHC may become the study of vertical circulation structures in the upper atmosphere and their variability under the action of external (solar and geomagnetic activities) and internal (stratospheric and tropospheric processes, the ocean and lithosphere effects) processes. Circulating cells due to vertical and horizontal transfer of active chemical components may significantly change the composition of the upper atmosphere, which may lead to significant variations in charged components, occurrence of additional heat sources, and other events and in the end may exert a considerable impact on space weather.

The capabilities of the stereoscopic methods for studying glowing structures suggest applicability of this method to NHC objectives. Observation of the total volume of the atmosphere with optical and radiophysical instruments of NHC, possibility of controlled influence on the upper atmosphere in this volume, and application of modern precision methods of optical spectroscopy and photometry will enable NHC to perform highquality research and will provide new research results.

The work was performed with budgetary funding of RAS Presidium Program No. 56 "Fundamental principal of breakthrough technologies in the interest of national security" and RFBR under research projects Nos. 18-0500594, 20-05-00212, 20-05-00580, and 19-35-90093. The work is based on data obtained using the optical complex of Center for Common Use "Angara" [http://ckp-rf.ru/ckp/3056]. 


\section{REFERENCES}

Astapovich I.O. Meteornye yavleniya $v$ atmosfere Zemli [Meteor phenomena in Earth's atmosphere]. Moscow, State Publishing House of Physics-Mathematical Literature 1958, 634 p. (In Russian).

Babadzhanov P.B., Obrubov Yu.V. Meteoroid swarm: formation, evolution, their relation to comets and asteroids. Astronomicheskii Vestnik [Astron. Bull.]. 1991, vol. 25, no. 4, p. 3 Moscow, 87. (In Russian).

Beletsky A.B., Mikhalev A.V., Chernigovskaya M.A., Sharkov E.A., Pokrovskaya I.V. Research into possibility of manifestation of tropical cyclone activity in Earth atmosphere proper airglow. Issledovanie Zemli iz kosmosa [Izvestiya, Atmospheric and Oceanic Physics]. 2010, no. 4, pp. 41-49. (In Russian).

Beletsky A.B., Mikhalev A.V., Khakhinov V.V., Lebedev V.P. Optical effects produced by running onboard engines of low-Earth-orbit spacecraft. Solar-Terrestrial Physics. 2016, vol. 2, iss. 4, pp. 107-117. DOI: 10.12737/24277.

Bernhardt P.A., Wong M., Huba J.D., Fejer B.J., Wagner L.S., Goldstain J.A., Selcher G.A., Frolov V.L., Sergeev E.N. Optical remote sensing of the thermoshere with HF pumped artificial airglow. J. Geophys. Res. 2000, vol. 105, no. A5, pp. 10657-10671.

Biondi A.A., Sipler D.P., Hake R.D. Optical $(\lambda 6300)$ detection of radio frequency heating of electrons in the $\mathrm{F}$ region. J. Geophys. Res. 1970, vol. 75, no. 31, pp. 6421. DOI: $10.1029 / \mathrm{JA075i031p06421.}$

Borovička J., Spurný P., Keclíková J. A new positional astrometric method for all-sky cameras. Astronomy and Astrophysics Supplement. 1995, vol. 112, pp. 173-178.

Chapman S. Geomagnetismus. Oxford, 1940, vol. 1-2, 149 p.

Clemesha B.R., de Medeiros A.F., Gobbi D., Takahashi H., Batista P.P., Taylor M.J. Multiple wavelength optical observations of a long-lived meteor trail. Geophys. Res. Lett. 2001, vol. 28, no. 14, pp. 2779-2782. DOI: 10.1029/2000GL012605. $386 \mathrm{p}$.

Cooray V. An Introduction to Lightning. Springer 2015.

Ermilov S.Yu., Mikhalev A.V. Fast variations in midlatitude sky optical radiation. Issledovaniya po geomagnetizmu, aeronomii i fizike Solntsa [Research on Geomagnetism, Aeronomy and Solar Physics]. Moscow, Nauka Publ., 1989, vol. 84, pp. 119-125. (In Russian).

Ermilov S.Yu., Mikhalev A.V. Optical manifestation of microbursts of electron fluxes. J. Atmos. Terr. Phys. 1991, vol. 53, no. $11 / 12$, pp. $1157-1160$.

Fabre F., Marini A., Sidler T., Morancais D., Fongy G., Vidal $\mathrm{Ph}$. A demonstrator for an incoherent Doppler wind lidar receiver. Proc. SPIE. 2018, vol. 10570, 1057005.

Gavrilova L.A. Diffuse transmission of upper-layer night airglow by the atmosphere. Izvestiya Atmospheric and Oceanic Physics. 1987, vol. 23, no. 10, pp. 817-820.

Gorelyi K.I., Degtyarev V.I., Kurilov V.A. The origin of fluctuations of the ratio of basic auroral emissions during substorms. Issledovaniya po geomagnetizmu, aeronomii i fizike Solntsa [Research on Geomagnetism, Aeronomy and Solar Physics]. Moscow, Nauka Publ., 1977, iss. 43, pp. 86-89. (In Russian).

Issledovanie radiatsionnykh kharakteristik aerozolya $\mathrm{v}$ Aziatskoi chasti Rossii [Research into radiative characteristics of aerosol in Asian part of Russia]. Ed. S.M. Sakerin. Tomsk, IOA SB RAS Publ., 2012, 484 p.

Ivanov K.I., Komarova E.S., Vasilyev R.V., Eselevich M.V., Mikhalev A.V. Meteor trail drift research based on baseline observations. Solar-Terrestrial Physics. 2019, vol. 5, iss. 1, pp. 7781. DOI: 10.12737/stp-51201911.

Kelley M.C., Gardner C., Drummond J., Armstrong T., Liu A., Chu X., Papen G., Kruschwitz C., Loughmiller P., Grime B., Engelman J. First observations of long-lived meteor trains with resonance lidar and other optical instruments. Geophys. Res. Lett. 2000, vol. 27, no. 13, pp. 1811-1814. DOI: 10.1029/1999GL011175.

Komarova E.S., Mikhalev A.V. Manifestation of Leonids meteor activity in the Earth's upper atmosphere radiation. Sovremennye problemy distantsionnogo zondirovaniya Zemli iz kosmosa [Current problems in remote sensing of the Earth from space]. 2014, vol. 11, iss. 2, pp. 277-287. (In Russian).

Kouahla M.N., Moreels G., Faivre M., Clairemidi J., Meriwether J.W., Lehmacher G.A., Vidal E., Veliz O. 3D Imaging of the $\mathrm{OH}$ mesospheric emissive layer. Adv. Space Res. 2010, vol. 45, pp. 260-267.

Lu M.-R., Chen P.-Y., Kuo C.-L., Chou C.-C., Wu B.-X., Shinsuke A., Su H.-T., Hsu R.-R., Wang S.-H., Lin N.-H., Lee L.-C. Recent work on sprite spectrum in Taiwan. Terr. Atmos. Oceanic Sci. 2017, vol. 28, no. 4. DOI: 10.3319/TAO. 2016.08.26.02.

Ma J., Xue X., Dou X., Chen T., Tang Y., Jia M., Zou Z., Li T., Fang X., Cheng X., Sun Sh. Large-scale horizontally enhanced sodium layers coobserved in the midlatitude region of China. J. Geophys. Res.: Space Phys. 2019, vol. 124, no. 9. pp. 7614-7628.

Martynenko V.V. Zadachi i metody lyubitelskikh nablyudenii meteorov [Tasks and Methods of Amateur Meteor Observations. Moscow, Nauka Publ., 1967, 77 p. (In Russian).

McKinley D. Metody meteornoi astronomii [Methods of meteor astronomy]. Moscow, Mir Publ., 1964, 383 p.

Medvedev A.V., Ratovsky K.G., Tolstikov M.V., Vasilyev R.V., Artamonov M.F. Method for determining neutral wind velocity vectors using measurements of internal gravity wave group and phase velocities. Atmosphere. 2019, vol. 10, no. 9. DOI: 10.3390/atmos10090546.

Medvedeva I., Ratovsky K. Studying atmospheric and ionospheric variabilities from long-term spectrometric and radio sounding measurements. J. Geophys. Res.: Space Phys. 2015, vol. 120, iss. 6, pp. 5151-5159. DOI: 10.1002/ 2015JA021289.

Medvedeva I.V., Ratovsky K.G. Solar activity influence on the mesopause temperature and F2 peak electron density. 2019 PhotonIcs \& Electromagnetics Research Symposium Spring (PIERS - SPRING). 2019, pp. 3958-3964.

Medvedeva I.V., Semenov A.I., Pogoreltsev A.I., Tatarnikov A.V. Influence of sudden stratospheric warming on the mesosphere/lower thermosphere from the hydroxyl emission observations and numerical simulations. J. Atmos. Solar-Terr. Phys. 2019, vol. 187, pp. 22-32. DOI: 10.1016/j.jastp.2019. 02.005 .

Mikhalev A.V. Mid-latitude Airglow During Heliogeophysical Disturbances. Geomagnetism and Aeronomy. 2011, vol. 51, no. 7, pp. 974-978.

Mikhalev A.V., Popov M.S., Kazimirovsky E.S. The manifestation of seismic activity in $557.7 \mathrm{~nm}$ emission variations of the Earth's upper atmosphere. Adv. Space Res. 2001, vol. 27, no. 6-7, pp. 1105-1108.

Mikhalev A.V. The Earth's upper atmosphere radiation in [OI] $557.7 \mathrm{~nm}$ emission during seismic events in Baikal Rift Zone. Optika atmosfery $i$ okeana [Atmospheric and Oceanic Optics]. 2016, vol. 29, iss. 12, pp. 1068-1072. (In Russian).

Mikhalev A.V., Tashchilin M.A. Some problems in solarterrestrial physics related to formation and dynamics of atmospheric aerosol. Optika atmosfery $i$ okeana [Atmospheric and Oceanic Optics]. 2007, vol. 20, no. 6, pp. 555-558. (In Russian).

Mikhalev A.V., Khakhinov V.V., Beletsky A.B., Lebedev V.P. Optical effects of functioning of Progress M17-M on-board engine at thermospheric heights. Kosmicheskie issledovaniya [Cosmic Res.]. 2016, vol. 54, no. 2, pp. 113-118. (In Russian).

Mikhalev A.V., Beletsky A.B., Vasilyev R.V., Podlesny S.V., Tashchilin M.A., Artamonov M.F. Spectral and photometric characteristics of mid-latitude auroras during 
the magnetic storm of March 17, 2015. Solar-Terr. Physics. 2018, vol. 4, iss. 4, pp. 42-47. DOI: 10.12737/stp-44201806.

Mikhalev A.V., Tashchilin M.A., Sakerin S.M. Atmospheric aerosol effect on results of ground-based observations of the upper atmosphere radiation. Optika atmosfery i okeana [Atmospheric and Oceanic Optics]. 2019, vol. 32, no. 3, pp. 202-207. (In Russian).

Mikhalev A.V., Vasilyev R.V., Beletsky A.B. Effects of short-duration increase in intensity of atomic oxygen [OI] $630.0 \mathrm{~nm}$ emission at lower thermosphere heights caused by technogenetics activity. Geomagnetizm $i$ aeronomiya [Geomagnetism and Aeronomy]. 2020, vol. 60, no. 1, pp. 116-125. (In Russian).

Nicoll K.A. Space weather influences on atmospheric electricity. Weather. 2014, vol. 69, no. 9, pp. 238-241. DOI: 10.1002/wea.2323.

Nwankwo V., Chakrabarti S., Weigel B. The effect of solar forcing induced atmospheric perturbations on LEO satellites' nominal aerodynamic drag. $42^{\text {nd }}$ COSPAR Scientific Assembly. 14-22 July 2018, Pasadena, California, USA. 2018. Abstract id. PSD.1-12-18.

Oppenheim M.M., Dimant Y. Meteor trails in the lower thermosphere: what do large radars really detect? // American Geophysical Union, Fall Meeting 2014, abstract id.SA41D-02.

Owens M.J., Scott C.J., Bennett A.J., Thomas S.R., Lockwood M., Harrison R.G., Lam M.M. Lightning as a spaceweather hazard: UK thunderstorm activity modulated by the passage of the heliospheric current sheet. Geophys. Res. Lett. 2015, vol. 42, no. 22, pp. 9624-9632. DOI: 10.1002/2015GL066802.

Pedatella N.M., Chau J.L., Schmidt H., Goncharenko L.P., Stolle C., Hocke K., Harvey V.L., Funke B., Siddiqui T.A. How sudden stratospheric warming affects the whole atmosphere. Eos. 2018, vol. 99. DOI: 10.1029/2018EO092441.

Rishbeth H. The effect of winds on the ionospheric F2-peak. J. Atmos. Terr. Phys. 1967, vol. 29, no. 3, pp. 225-238. DOI 10.1016/0021-9169(67)90192-4.

Rudawska R., Zender J., Koschny D., Smit H., Lohle S., Zander F., Eberhart M., Meindl A., Latorre I. A spectroscopy pipeline for the Canary island long baseline observatory meteor detection system. Planetary and Space Science. 2020, vol. 180, 104773.

Shefov N.N., Semenov A.I., Khomich V.Yu. Izluchenie verkhnei atmosfery - indicator ee struktury i dinamiki [The upper atmosphere radiation as an indicator of its structure and dynamics]. Moscow, GEOS Publ., 2006, 741 p. (In Russian).

Shindin A.V., Klimenko V.V., Kogogin D.A., Beletsky A.B., Grach S.M., Nasyrov I.A., Sergeev E.N. Spatial Characteristics of the 630-nm Artificial Ionospheric Airglow Generation Region During the Sura Facility Pumping. Radiophysics and Quantum Electronics. 2018, vol. 60, no. 11, pp. 849-865. DOI: 10.1007/s11141-018-9852-0.

Shiokawa K., Ogawa T., Kamide Y. Low-latitude auroras observed in Japan: 1999-2004. J. Geophys. Res. 2005, vol. 110, pp. A05202. DOI: 10.1029/2004JA010706.

Shiokawa K., Otsuka Y., Oyama S., Nozawa S., Satoh M., Katoh Y., et al. Development of low-cost sky-scanning Fabry - Perot interferometers for airglow and auroral studies. Earth, Planets and Space. 2012, vol. 64, pp. 1033-1046. DOI: 10.5047/eps.2012.05.004.

Siingh D., Singh R.P., Singh A.K., Kulkarni M.N., Gautam A.S., Singh A.K. Solar activity, lightning and climate. Surveys in Geophysics. 2011, vol. 32, no. 6, pp. 659-703. DOI: 10.1007/s10712-011-9127-1.

Tashchilin M.A., Beletsky A.B., Mikhalev A.V., Xu Jiyao, Yuan We. Some results of observation of spatial inhomogeneities in hydroxyl emission. Solnecho-zemnaya fizika [Solar-Terr. Phys.]. 2010, iss.15, pp. 131-134. (In Russian).
Tkachev I.D., Vasilyev R.V., Mikhalev A.V., Podlesny S.V., Setov A.G. Recording optical flashes in the night atmosphere from CCD photometer. Proc. SPIE 10466, $23^{\text {rd }}$ International Symposium on Atmospheric and Ocean Optics: Atmospheric Physics. 30 November 2017. 1046648. DOI: 10.1117/12.2288293.

Tkachev I.D., Vasilyev R.V., Mikhalev A.V., Podlesny S.V. Simultaneous observations of fast optical events in the Earth's atmosphere by optical devices complex. Proc. SPIE 11208, $25^{\text {th }}$ International Symposium on Atmospheric and Ocean Optics: Atmospheric Physics. 18 December 2019. 112089C. DOI: 10.1117/12.2540839.

Toroshelidze T.I., Fishkova L.M. Analysis of oscillations of the middle and upper atmosphere night airglow preceding earthquakes. Doklady AN SSSR [Doklady Earth Sciences]. 1988, vol. 302, no. 2, pp. 313-316. (In Russian).

Vasilyev R.V., Artamonov M.F., Beletsky A.B., Zherentsov G.A., Medvedeva I.V., Mikhalev A.V., Syrenova T.E. Registering upper atmosphere parameters in East Siberia with Fabry-Perot Interferometer KEO Scientific "Arinae". Solar-Terrestrial Physics. 2017, vol. 3, iss. 3, pp. 61-75. DOI: $10.12737 /$ stp-33201707.

Vasilyev R.V., Artamonov M.F., Merzlyakov E.G. Comparative statistical analysis of neutral wind in mid-latitude mesosphere / lower thermosphere based on meteor radar and Fabry-Perot interferometer data. Solar-Terrestrial Physics. 2018, vol. 4, iss. 2, pp. 49-57. DOI: 10.12737/stp-42201808.

Vorontsov-Velyaminov V.A. Ocherki o vselennoi. Khimicheskii sostav Zemli i meteoritov [Esseys about the Universe. Chemical Composition of Earth and Meteorites]. Moscow, Nauka Publ., 1969, vol. 1, 476 p.

Whiter D.K., Gustavsson B., Partamies N., Sangalli L. A new automatic method for estimating the peak auroral emission height from all-sky camera images. Geoscientific Instrumentation, Methods and Data Systems. 2013, vol. 2, pp. 131-144. DOI: 10.5194/gi-2-131-2013.

Wu Q., Li H., Wang C. Lightning response during Forbush Decrease in the tropics and subtropics. J. Atmos. Solar-Terr. Phys. 2019, vol. 195, article id. 105134. DOI: 10.1016/j.jastp.2019. 105134. 2019).

URL: http://ckp-rf.ru/ckp/3056 (accessed 30 September

How to cite this article

Vasilyev R.V., Artamonov M.F., Beletsky A.B., Zorkaltseva O.S., Komarova E.S., Medvedeva I.V., Mikhalev A.V., Podlesny S.V., Ratovsky K.G., Syrenova T.E., Tashchilin M.A., Tkachev I.D. Scientific goals of optical instruments of the National Heliogeophysical Complex. Solar-Terrestrial Physics. 2020. Vol. 6. Iss. 2. P. 84-97. DOI: 10.12737/stp-62202008. 